\title{
A PERCEPÇÃO DO PSICÓLOGO SOBRE O USO DA EQUOTERAPIA NOS PORTADORES DO TRANSTORNO DO ESPECTRO AUTISTA
}

Aline Larrissa Trombini Fernandes ${ }^{1}$ orcid.org/0000-0001-5187-1576; Ediely Ferreira Casagrande ${ }^{2}$ orcid.org/0000-0003-1412-3231, Jackeline Baraldo Zampar ${ }^{3}$ orcid.org/0000-0003-1222-1380, Lucyanne de Souza Meira ${ }^{4}$ orcid.org/0000-0002-1980-0644, Leonardo Pestillo de Oliveira ${ }^{5}$ orcid.org/0000-0001-5278-0676, Paula Farineli de Souza ${ }^{6}$ orcid.org/0000-0002-7942-3932, Lucas França Garcia ${ }^{7}$ orcid.org/0000-0002-5815-6150, Marcos Paulo Shiozaki ${ }^{8}$ orcid.org/0000-0003-2123-786X

RESUMO. Este artigo descritivo com abordagem qualitativa tem como objetivo conhecer as características das crianças portadoras do Transtorno do Espectro Autista (TEA), compreender a prática equoterápica, relacionar a equoterapia com o TEA e identificar a percepção de psicólogos sobre a importância da equoterapia no tratamento do autismo. Primeiramente realizou-se uma pesquisa bibliográfica para conhecer as características e os sintomas do autismo em geral, a identificação pelos pais, e o modo geral como acontece a prática equoterápica em crianças. A pesquisa de campo foi composta por uma entrevista semiestruturada aplicada em duas psicólogas e foi realizada uma análise de conteúdo das respostas, o que possibilitou verificar a percepção que os psicólogos têm sobre os benefícios trazidos pela prática da equoterapia em crianças portadoras do TEA. A prática equoterápica foi descrita como um importante recurso que contribui para o desenvolvimento de crianças com TEA. Além da melhora do equilíbrio, da coordenação motora, consciência corporal, da respiração e das capacidades cardiovasculares, enfatizou-se também o aspecto afetivo e emocional do praticante, auto estima e potencializador da confiança do praticante.

Palavras-chave: [Equoterapia. Transtorno do Espectro Autista. Psicologia.]

THE PSYCHOLOGIST'S PERCEPTION ABOUT THE USE OF EQUINEASSISTED THERAPY IN PATIENTS WITH AUTISTIC SPECTRUM DISORDER

${ }^{1}$ Centro Universitário Maringá-UniCesumar; aline.larrissaf@ gmail.com ${ }^{2}$ Centro Universitário MaringáUniCesumar; ediely_guapi.2011@ @otmail.com ${ }^{3}$ Centro Universitário Maringá-UniCesumar; jackzampar@ hotmail.com ${ }^{4}$ Centro Universitário Maringá-UniCesumar; prof.lucyanne@ gmail.com ${ }^{5}$ Centro Universitário Maringá-UniCesumar; leopestillo@gmail.com ${ }^{6}$ Centro Universitário MaringáUniCesumar; paulafarineli@ hotmail.com ${ }^{7}$ Centro Universitário Maringá-UniCesumar; lucasfgarcia@gmail.com ${ }^{8}$ Universidade Estadual de Maringá-UEM; marcos.shiozaki@gmail.com 
ABSTRACT. This descriptive article with a qualitative approach aims to know the characteristics of children with Autistic Spectrum Disorder (ASD), understand the therapeutic practice, relate equine-assisted therapy to ASD and identify the perception of psychologists on the importance of equine-assisted therapy in the treatment of autism. Firstly, a bibliographic research was carried out to find out the characteristics and symptoms of autism in general, the identification by parents, and the general way in which equine-assisted therapy occurs in children. The field research was composed of a semistructured interview applied to two psychologists and for the analysis of the results, the Underlying Discourse Explanation Method was used. The analysis of the contents generated analytical categories for a better understanding of the results: the perception that psychologists have about the benefits brought by the practice and the general way in which equine-assisted therapy occurs in children in children with ASD. Equine-assisted therapy has been described as an important resource that contributes to the development of children with ASD. In addition to improving balance, motor coordination, body awareness, breathing and cardiovascular capabilities, the practitioner's affective and emotional aspect, self-esteem and enhancer of the practitioner's confidence were also emphasized.

Keywords: [Equine-Assisted Therapy. Autistic Spectrum Disorder. Psychology.]

\section{Introdução}

A Psicologia Contemporânea explora um campo de psicopatologias que estão atreladas ao contexto vivido e, por conta desse fato, mostra uma infinidade de questões complexas que envolvem uma única psicopatologia. O transtorno do espectro autista, sem dúvidas, gera no portador inúmeras dificuldades para enfrentar o dia a dia com normalidade. A quinta edição do Manual Diagnóstico e Estatístico dos Transtornos Mentais (DSM-5) caracteriza os tais portadores a se desenvolverem com mais naturalidade, se utilizam da técnica equoterápica. De acordo com a Associação Nacional de Equoterapia (ANDE-BRASIL, 1999), entidade responsável pela criação deste nome, o termo tem o objetivo de caracterizar todas as práticas que utilizam o cavalo como métodos de equitação e atividades equestres, com o propósito de alcançar a reabilitação e a educação de pessoas com deficiência ou com necessidades especiais. 
[v.1, n.1] Jul./Dez.2020

Portanto, a presente pesquisa consiste, primeiramente, em conhecer as características das crianças portadoras do espectro autista, para relacioná-la, posteriormente, com a equoterapia, que vem ganhando um espaço cada vez mais expressivo como uma possibilidade terapêutica.

Dessa forma, além de conhecer as características das crianças portadoras dessa afecção, visou-se compreender a prática equoterápica, relacionar a equoterapia com o Transtorno do Espectro Autista e identificar a percepção de psicólogos sobre a importância da equoterapia no tratamento do autismo.

No Brasil há algumas instituições que para ajudar tais portadores a se desenvolverem com mais naturalidade, praticam a técnica da equoterapia. Embora a prática equoterápica tenha sua importância reconhecida conforme Alves (2015) como "método médico", há pouquíssimo material escrito sobre o assunto. Severo (2010, p. 19) também cita:

[...] é um método de intervenção terapêutica que utiliza a relação com o cavalo, com técnicas de equitação e atividades equestres como recursos para auxiliar no desenvolvimento por meio do movimento tridimensional e de atividades lúdicas.

Assim sendo, poderiam existir mais pesquisas que relacionem ambos os temas: o Transtorno do Espectro Autista e a equoterapia. Para tanto, surgiu essa temática de pesquisa, que visa entender a visão do psicólogo sobre o uso da equoterapia com os portadores do Transtorno do Espectro Autista. A partir do conhecimento das características psicomotoras de um portador e do funcionamento da prática equoterápica, será possível estabelecer uma relação entre ambos os temas, interligando a visão que o psicólogo tem sobre essa parceria.

\section{Métodos}

Este trabalho utilizou como um dos seus métodos a pesquisa bibliográfica, em que revisou questões já estabelecidas por outros pesquisadores, além da pesquisa de campo que consistiu em se dirigir até os sujeitos com a devida autorização em busca de dados para compor os resultados.

Os sujeitos da pesquisa foram duas psicólogas, da cidade de Cianorte, e Maringá, todas do Estado do Paraná, graduadas em Psicologia, licenciados na prática equoterápica 
[v.1, n.1] Jul./Dez.2020

e atendendo crianças portadoras do espectro autista em APAES ou centros especializados, caracterizando assim o critério de inclusão da respectiva pesquisa. Psicólogos que não atendem essa demanda da equoterapia e não residam nas cidades em pauta estão nos critérios de exclusão.

Realizou-se uma entrevista com cada psicóloga das diferentes cidades. Durante a realização, a pesquisadora aplicou um questionário semiestruturado, em que as profissionais tiveram maior liberdade em suas respostas pelo fato de não serem perguntas objetivas. A coleta de dados se deu individualmente e ocorreu em um período de 60 minutos. Por se tratar de uma pesquisa qualitativa, o método utilizado foi a análise de conteúdo das respostas.

Essa pesquisa foi devidamente aprovada pelo Comitê de Ética em Pesquisa Universidade UniCesumar, sob o parecer 1.627.135.

\section{Resultados}

Transtorno do Expectro Autista (TEA)

A partir das pesquisas realizadas sobre TEA, observou-se que um país se destacou em pesquisas em relação a este tema, de acordo com Pereira, Riesgo e Wagner (2008), nos Estados Unidos (EUA), há uma proporção em que a cada 1.000 crianças, pelo menos 1 será diagnosticada como portadora do TEA.

Para Ana Melo (2007) o TEA é uma síndrome, e o que a define são as alterações existentes desde muito cedo, geralmente antes dos três anos de idade, e que se caracteriza sempre por desvios qualitativos na comunicação, na interação social e na utilização da linguagem.

Os autores Zannon, Backes e Bossa (2014) contribuem sobre o assunto e ressaltam que indivíduos portadores de tal transtorno apresentam aversão, ansiedade ou medo de contato social.

Outras características que podem ser observadas além dessas já citadas anteriormente, são as trazidas por Klin (2006), presença de maneirismos estereotipados e imitação social. Que nada mais são, que comportamentos que se repetem constantemente, como balançar o tronco para frente e para trás, balançar as mãos, entre outros. 
[v.1, n.1] Jul./Dez.2020

\section{Beneficios da equoterapia em crianças com TEA}

Os sujeitos desta pesquisa descreveram a equoterapia como uma prática benéfica aos portadores do TEA, pois foi caracterizado como um ambiente seguro, onde as crianças são estimuladas em todos os sentidos, como psicomotor, fala, toque, entre outros. E achou-se na literatura pesquisas que comprovam tais benefícios, como:

"A equoterapia emprega o cavalo como agente promotor de ganhos a nível físico e psíquico. Esta atividade exige a participação do corpo inteiro, contribuindo, assim, para o desenvolvimento da força muscular, relaxamento, conscientização do próprio corpo e aperfeiçoamento da coordenação motora e do equilíbrio. A interação com o cavalo, incluindo os primeiros contatos, os cuidados preliminares, o ato de montar e o manuseio final desenvolvem, ainda, novas formas de socialização, autoconfiança e autoestima". (ASSOCIAÇÃO NACIONAL DE EQUOTERAPIA, 2015)

A partir dos dados coletados na entrevista, se tornou perceptível o funcionamento prático da equoterapia. De acordo com as psicólogas entrevistadas, foi possível visualizar que a prática da equoterapia traz muitos acrescentamentos como se pode observar nos relatos das psicologas $1(\mathrm{P} 1)$ e $2(\mathrm{P} 2)$.

"Sim, a prática da equoterapia desenvolvido através de programa de atividades físicas durante a Equoterapia, tem como objetivo a melhora do equilíbrio, da coordenação motora, consciência corporal, da respiração e das capacidades cardiovasculares, enfatizando também o aspecto afetivo e emocional do praticante, auto estima e potencializar a confiança do praticante" (P1).

"A prática da equoterapia traz muitos benefícios ao portador, atualmente há uma demanda muito alta principalmente após o DSM-5 né, porque antes era considerado outro tipo de patologia. Os autistas clássicos possuem uma rotina fixa e na clínica, o ambiente sendo fechado não proporciona condições agradáveis para a criança. Aí na prática equoterápica o ambiente está sempre em constante transformação, há presença de barulhos, chuva, vento, com isso o autista adquire maior flexibilidade e aceita as mudanças aos quais está sendo submetido" (P2). 
[v.1, n.1] Jul./Dez.2020

Conforme Ferrari (2003), a equoterapia é um tratamento voltado diretamente à área da saúde e direcionado principalmente para pessoas portadoras tanto de uma deficiência física quanto mental, possuindo assim, deficiências motoras, sensoriais, mentais, inadaptações sociais diversas, nas quais o sujeito não consegue manter-se sozinho sobre o cavalo, necessitando assim, de um auxiliar-guia para conduzir o cavalo e por ventura, de um auxiliar-lateral para que o mesmo não corra risco de cair. A partir disso, é indubitável a importância de um terapeuta ou mediador para a execução dos exercícios a serem realizados.

Em relação ao tempo que leva para notar tais benefícios em relação à equoterapia, as psicólogas destacam:

"Os resultados aparecem de acordo com a particularidade de cada praticante, dependendo de cada diagnóstico. Em alguns praticantes vemos os resultados logo nos primeiros meses, dependendo do grau de comprometimento de cada praticante"(P1).

"Cada criança possui seu universo particular, ou seja, seu próprio tempo, nós não forçamos e também não comparamos umas com as outras. maioria dos alunos têm uma ótima receptividade, adequação ao animal e a prática equoterápica em si. Em alguns casos, como por exemplo, praticantes com o diagnóstico de autismo com grau elevado, o trabalho de sensibilização tem uma durabilidade maior. (P2).

Em relação aos benefícios do ambiente onde é realizado tal prática, as psicólogas citaram:

"Nossa, na clínica por exemplo nós temos uma rotina fixa, com o ambiente fechado né, já aqui o ambiente está sempre se transformando, tem barulho, chuva, vento, isso ajuda muito eles porque a maioria tem dificuldade em sair da rotina né, então aqui eles são constantemente estimulados a se adaptarem”(P1).

"Para os autistas é muito importante essa dinâmica do centro aqui, não há uma rotina fixa, é mais livre e eles aprendem a conviver com isso, e isso se reflete no dia a dia deles depois. Os cavalos são alternados pelo motivo de gerar familiaridade da criança com todos os cavalos presentes no centro. Vale lembrar também, que a questão de todos 
[v.1, n.1] Jul./Dez.2020

possuírem seu próprio universo permanece muito forte no processo de configuração das sessões"(P2).

Conforme Medeiros e Dias (2002), o alinhamento do centro de gravidade homem/cavalo é capaz ativar o sistema nervoso, alcançando resultados como a melhora do equilíbrio, ajuste tônico, alinhamento corporal, consciência corporal, coordenação motora e força muscular. Tendo o deslocamento no movimento tridimensional, há a estimulação de diversos sistemas sensoriais, permitindo benefícios psíquicos, lapidando o aprendizado visual e auditivo, cooperando também para o equilíbrio e a conscientização corporal da pessoa portadora de necessidades especiais. Dessa forma o sujeito adquire maior flexibilidade e aceita as mudanças pelas quais está sendo submetido, e há um progresso significativo na evolução da linguagem, o que se observa nos excertos:

“Com o passar do tempo a sessão muda de configuração, conforme o praticante for respondendo ao tratamento, as sessões vão mudando utilizando outras formas de trabalho na prática para se trabalhar com cada praticante"(P1).

"De início, é feito um trabalho de solo, carícias no cavalo, escovam os pelos até haver a familiarização com o animal. Após isso, a criança consegue seguir os comandos adquirindo coordenação na montaria. A criança participa de todos os processos envolvidos na prática, desde dar banho, alimentar o cavalo e dar água. Tem dias em que eles não aceitam a montaria e simplesmente optam por alimentá-los e cuidá-los”(P2).

\section{Restrições da prática Equoterápica}

Percebe-se algumas restrições nos excertos de uma das psicólogas:

"Há restrição nos casos em que os pacientes possuem alguma alergia em relação ao cavalo ou crianças que possuem o comportamento de muita resistência ao contato, então para esses pacientes a gente não insiste, porque pode prejudicá-los ainda mais né, em relação ao estresse, ansiedade"(P1).

$\mathrm{Na}$ literatura não foi encontrado dados a respeito.

Contribuição da Equoterapia para o processo de desenvolvimento emocional

Verificou-se que a equoterapia contribui para o processo de desenvolvimento emocional, por estar ligada à expressão de afetos, conforme o relato das psicólogas: 
[v.1, n.1] Jul./Dez.2020

“O animal por si só já desempenha uma presença viva, afetiva e concreta né, o que evoca sentimentos e emoções. A gente vê alegria, serenidade, medo, raiva, tristeza, vários sentimentos. Então, não é interessante considerar apenas as estimulações, as funções motoras e psicomotoras que o andar a cavalo propicia, mas também o componente racional que é desenvolvido entre a pessoa e o animal que engrandece este tipo de terapia, e o que o torna um agente facilitador para uma intervenção psicoterápica.”(P1)

"A equoterapia contribui para o processo de desenvolvimento emocional porque está ligada à expressão afetiva. O autista não dá espaço para ser compreendido pelas pessoas e a partir da relação com o cavalo, consegue se expressar dando sentido ao que sente, é nesse momento em que o profissional pode colocar em palavras o que não tem palavras, através de sentimentos, afetos, fazendo com que possa entenda que está ali disposto a ajudar, mesmo não dizendo, muitas vezes apenas sorrindo.”(P2)

Conforme Souza et al (2015, p. 57-58)

[...] a Equoterapia favorece a reintegração social, que é estimulada pelo contato do indivíduo com outros pacientes, com a equipe e com o animal, aproximando-o desta maneira, cada vez mais, da sociedade na qual convive.

Profissionais necessários para a realização da prática de equoterapia em crianças com TEA

Segundo a Associação Nacional de Equoterapia (2015), os profissionais necessários consistem, no mínimo um psicólogo, um fisioterapeuta e um profissional de equitação.

Ao serem questionadas, as psicólogas responderam:

"Aqui nós contamos com um psicólogo, um fisioterapeuta, um profissional de equitação, uma fonoaudióloga, um zootecnista, um psicomotricista e uma psicopedagoga"(P1).

"Psicóloga, fisioterapeuta, educador físico e em algumas sessões a fonoaudióloga faz algumas intervenções"(P2).

\section{Conclusão}

O objetivo da pesquisa foi analisar a percepção do psicólogo sobre o uso da equoterapia nos portadores do Transtorno do Espectro Autista. Entre as psicólogas 
[v.1, n.1] Jul./Dez.2020

entrevistadas foi possível perceber o quanto ambas acreditam nos benefícios que a equoterapia pode trazer na vida de pessoas com alguma deficiência, especialmente com os portadores de TEA que tiveram maior foco no estudo. No entanto, foi possível perceber poucos trabalhos que relacionem esses dois temas. E isso demonstrou que mais pesquisas devem ser feitas.

É preciso pensar na equoterapia como um método médico que visa melhorar o desenvolvimento e qualidade de vida desses pacientes. A atratividade proporcionada pela relação entre o cavalo e sujeito deve ser aproveitada ao máximo, estimulando assim o engajamento desses participantes. A questão lúdica que é tão importante na prática clínica na psicologia, é possível ser trazida ao tratar com o animal, ao alimentá-lo, lavá-lo, enfim, ao tratá-lo, não somente no momento prático da montaria.

Promover a saúde desses pacientes de maneira holística é fundamental. Pois muitas práticas visam a melhora de uma parte específica da pessoa, mas a prática de equoterapia pode alcançar diversos níveis, como comportamentais e cognitivos.

Algumas limitações podem ser ressaltadas a partir da realização deste estudo. Uma delas é sobre a quantidade de psicólogos entrevistados, já que não há muitos profissionais especializados e que trabalham com esse público-alvo do estudo. No entanto, por se tratar de uma pesquisa qualitativa, a abrangência dos dados pode ser considerada significativa.

\section{Referências}

Alves, H. M. (2015). Corpo e Linguagem na Equoterapia: Uma Leitura Psicanalítica. Brasília.

American Psychiatric Association. (2013). Manual diagnóstico e estatístico de transtornos mentais ( $5^{\text {a }}$ ed.). https://doi.org/10.1176/appi.books.9780890425596

Associação Nacional de Desenvolvimento da Equoterapia (ANDE-BRASIL 2015). Apostila Brasília, DF.

Associação Nacional de Desenvolvimento da Equoterapia (ANDE-BRASIL 1999). Apostila Brasília, DF.

Juliana, P.F. (2003). A Prática do Psicólogo na Equoterapia. São Paulo. 
[v.1, n.1] Jul./Dez.2020

Klin, A. (2006) Autismo e síndrome de Asperger: uma visão geral. Rev. Bras.

Psiquiatr., São Paulo v. 28, supl. 1, p. s3-s11, May.

Medeiros, M; Dias, E. (2002). Equoterapia: bases e fundamentos. Rio de Janeiro:

Revinter.

Mello, A. (2007) Autismo: Guia Prático. São Paulo.

Pereira, A. ; Riesgo, R. S.; Wagner, M. B. (2008). Autismo infantil: tradução e validação da Childhood Autism Rating Scale para uso no Brasil. J. Pediatr. (Rio J.), Porto Alegre, v. 84 , n. 6 , p. $487-494$, Dec.

Severo, J. T. (2010). Equoterapia: equitação, saúde e educação. São Paulo: Editora Senac.

Souza, M. B. e Silva, P. de L. N. (2015). Equoterapia no Tratamento do Transtorno do Espectro Autista: A percepção dos técnicos.

Zanon, R. B.; Backes, B.; Bosa, C. A. (2014). Identificação dos primeiros sintomas do autismo pelos pais. Psic.: Teor. e Pesq., Brasília, v. 30, n. 1, p. 25-33, Mar. 